\title{
Sodium channel $\beta 2$ subunit promotes filopodia-like processes and expansion of the dendritic tree in developing rat hippocampal neurons
}

\section{Marta Maschietto ${ }^{\ddagger}$, Stefano Girardi ${ }^{\ddagger}$, Marco Dal Maschio ${ }^{\dagger}$, Michele Scorzeto and Stefano Vassanelli *}

Department of Biomedical Sciences, University of Padova, Padova, Italy

\section{Edited by:}

Dieter Wicher, Max Planck Institute

for Chemical Ecology, Germany

\section{Reviewed by:}

Mohamed Chahine, Laval University,

Canada

Juan José Garrido, Instituto Cajal,

Spain

\section{*Correspondence:}

Stefano Vassanelli, Department of Biomedical Sciences, University of Padova, via Marzolo 3,

35131 Padova, Italy.

e-mail: stefano.vassanelli@unipd.it

${ }^{\dagger}$ Present address:

Marco Dal Maschio, Italian Institute

of Technology, Genova, Italy.

¥ These authors equally contributed to this work.
The $\beta 2$ auxiliary subunit of voltage-gated sodium channels (VGSCs) appears at early stages of brain development. It is abundantly expressed in the mammalian central nervous system where it forms complexes with different channel isoforms, including $\mathrm{Na}_{v}$ 1.2. From the structural point of view, $\beta 2$ is a transmembrane protein: at its extracellular $\mathrm{N}$-terminus an Ig-like type C2 domain mediates the binding to the pore-forming alpha subunit with disulfide bonds and the interactions with the extracellular matrix. Given this structural versatility, $\beta 2$ has been suggested to play multiple functions ranging from channel targeting to the plasma membrane and gating modulation to control of cell adhesion. We report that, when expressed in Chinese Hamster Ovary cells CHO-K1, the subunit accumulates at the perimetral region of adhesion and particularly in large lamellipodia-like membrane processes where it induces formation of filopodia-like structures. When overexpressed in developing embryonic rat hippocampal neurons in vitro, $\beta 2$ specifically promotes formation of filopodia-like processes in dendrites leading to expansion of the arborization tree, while axonal branching remains unaltered. In contrast to this striking and highly specific effect on dendritic morphology, the targeting of functional sodium channels to the plasma membrane, including the preferential localization of $\mathrm{Na}_{v} 1.2$ at the axon, and their gating properties are only minimally affected. From these and previously reported observations it is suggested that $\beta 2$, among its multiple functions, may contribute to promote dendritic outgrowth and to regulate neuronal wiring at specific stages of neuronal development.

Keywords: sodium channel, $\beta 2$ subunit, filopodia, rat hippocampal neuron, CHO-K1

\section{INTRODUCTION}

Voltage-gated sodium channels (VGSCs) (Goldin et al., 2000; Catterall et al., 2005) are fundamental for neuronal excitability and action potential propagation. They are widely expressed within the nervous system as heteromeric transmembrane complexes of a pore-forming $\alpha$ subunit, existing in nine isoforms $\left(\mathrm{Na}_{\mathrm{v}} 1.1-\mathrm{Na}_{\mathrm{v}} 1.9\right)$, and at least one auxiliary $\beta$ subunit. Four $\beta$ subunits ( $\beta 1-\beta 4)$ have been identified (Catterall, 2000; Catterall et al., 2005): $\beta 1$ and $\beta 3$ are non-covalently linked to the $\alpha$ subunit, while $\beta 2$ and $\beta 4$ are disulfide-linked to $\alpha$ by means of their N-terminal Ig-like domain (Hartshorne et al., 1982; Morgan et al., 2000; Yu et al., 2003; Chen et al., 2012). Their C-terminus, instead, is a short 34 aminoacids region. $\beta$ subunits are seen as potential candidates to play multiple functions including shifting sodium channels voltage-dependence and regulating their surface expression or promoting cell-extracellular matrix and cell-cell adhesion interactions. Overall, they are emerging as modulators of cell excitability and adhesive properties encompassing a wide spectrum of actions within and outside the nervous system (Kaczmarek, 2006; Brackenbury and Isom, 2008; Brackenbury et al., 2008b; Patino and Isom, 2010).

The $\beta 2$ subunit makes no exception. Abundantly expressed in the rat brain, it is found associated with several $\mathrm{Na}_{\mathrm{v}}$ isoforms (Catterall et al., 2005) and following various timeand region-dependent patterns during development (Isom et al., 1995; Gastaldi et al., 1998; Gong et al., 1999; Chen et al., 2002). Regulating cell adhesion and migration-related events (Kaczmarek, 2006; Brackenbury et al., 2008b; Patino and Isom, 2010) and axonal growth (Srinivasan et al., 1998; Xiao et al., 1999) has been considered among its putative roles. Particularly, as a physiological substrate of $\beta$-site APP cleaving enzyme 1 (BACE1) and $\gamma$-secretase (Kim et al., 2005; Wong et al., 2005), two proteolytic enzymes central to Alzheimer's disease pathogenesis (Gandy, 2005), $\beta 2$ was found to affect adhesion/migration in CHO-K1 cells, besides regulating $\mathrm{Na}_{\mathrm{v}} 1.1 \mathrm{mRNA}$ and protein expression levels (Kim et al., 2005, 2007). Intriguingly, $\beta 2$ has been shown to heavily affect membrane morphology. Xenopus oocytes expressing $\beta 2$ were characterized by an increment of microvilli extension (Isom et al., 1995). Similarly, an increase of filopodia-like processes was induced in HEK293 cells (Zimmer et al., 2002). It is still unclear whether related functions could be relevant for neurons. On the other end, as expected for a channel auxiliary subunit, $\beta 2$ was shown to modulate $\mathrm{Na}_{\mathrm{v}}$ membrane expression and targeting (Malhotra et al., 2000; Pertin et al., 2005; Lopez-Santiago et al., 2006; O'Malley et al., 2009) and to shift $\mathrm{Na}_{\mathrm{v}}$ voltage-dependence of activation and inactivation. This latter 
effect appears to vary by cell type or stage of development in terms of extent and shifting direction (Isom et al., 1995; Qu et al., 2001; Chen et al., 2002; Yu et al., 2003).

In conclusion, $\beta 2$ has the potential to play variegated functions characterized by a channel modulator/adhesion molecule dualism. Certainly, the abundant expression in the mammalian central nervous system, including embryonic stages, supports the hypothesis that it plays a physiological role also during neuronal development. To deepen understanding of $\beta 2$ adhesion-related functions, particularly during development, we investigated the effect of $\beta 2$ expression first in $\mathrm{CHO}-\mathrm{K} 1$ cells and then in developing rat hippocampal neurons. By analyzing changes in cell morphology and the subcellular distribution of a newly synthesized $\beta 2$ fluorescent chimera with a combination of Total Internal Reflection Fluorescence (TIRF) and epifluorescence microscopy, we show that $\beta 2$ can act as adhesion molecule promoting outgrowth of filopodia-like processes and specifically enhancing branching of the dendritic tree in developing neurons.

\section{MATERIALS AND METHODS PLASMIDS AND CLONING STRATEGIES}

A $\beta 2$-ECFP chimera (subsequently named $\beta 2 \mathrm{C}$ ) was created by linking ECFP to the C-terminus of the rat brain $\beta 2$ subunit. The cDNA coding for the rat $\beta 2$ precursor (with $\mathrm{N}$-terminal signal peptide) was amplified from a donor vector (kindly given by Prof. A. L. Goldin, Department of Microbiology and Molecular Genetics, Department of Anatomy and Neurobiology, University of California, Irvine, CA, USA) with $5^{\prime}$ NheI and $3^{\prime}$ ApaI ends (forward primer: 5'cggGCTAGCcatgcacagggatgcctggct3'; reverse primer: $5^{\prime}$ atcGGGCCCgcgcttggcgccatctt $3^{\prime}$ ), restricted with specific enzymes (Promega, Italy) and cloned into linearized pcDNA3.1(-) (Invitrogen, Italy). The ECFP cDNA was amplified by PCR from a donor vector (kind gift by Prof. T. Pozzan, Department of Biomedical Sciences, University of Padova) with $5^{\prime}$ EcoRI and $3^{\prime}$ BamHI ends (for-

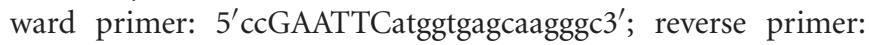
$5^{\prime}$ ggGGATCCggctacttgtacagctcg $3^{\prime}$; the ends are in capital letters, the stop codon is underlined), and subcloned in frame and downstream of $\beta 2$. The linker between $\beta 2$ and ECFP was the amino acid sequence GPSRLERPPLCWISAEF.

B2 cDNA was amplified from donor vector with $5^{\prime}$ EcoRI and $3^{\prime}$ BamHI ends (forward primer: 5'agGAATTCcatgcacagggatgcctggct $3^{\prime}$; reverse primer: $5^{\prime}$ cgcGGATCCgcgttacttggcgecatcttc $3^{\prime}$ ) and subcloned into pcDNA3.1(-) to express the subunit in mammalian cells without fluorescence at its C-terminus. EcoRI/BamHI amplified ECFP cDNA was subcloned alone into pcDNA3.1(-) for control transfections. All custom single strand oligonucleotides for PCRs (Sigma-Aldrich, Italy) were designed on GenBank cDNA sequences by means of Primer3 software (http://primer3. sourceforge.net/). PCR reactions were performed using alternatively Expand ${ }^{\mathrm{TM}}$ High Fidelity Taq (Roche) or Platinum ${ }^{\circledR}$ Taq DNA Polymerase (Invitrogen), according to the manufacturer's instructions. Cloning was verified by standard sequencing (BMR Genomics, Italy).

The rat brain $\mathrm{Na}_{\mathrm{v}} 1.2 \alpha$ subunit rIIA isoform (subsequently named $\mathrm{Na}_{\mathrm{v}} 1.2$ or $\alpha$; Auld et al., 1988), cloned into the mammalian expression vector pCDM8, was a kind gift of Prof. W. A. Catterall (Department of Pharmacology, University of Washington).

\section{CELL CULTURES AND TRANSFECTIONS}

CHO-K1 (ATCC, USA) were maintained in F-12 Nutrient Mixture-Ham-supplemented with $10 \%(\mathrm{v} / \mathrm{v})$ heat-inactivated FBS, $10 \mathrm{u} / \mathrm{ml}$ penicillin and $10 \mu \mathrm{g} / \mathrm{ml}$ streptomycin, in a humidified atmosphere at constant temperature $\left(37^{\circ} \mathrm{C}\right)$ and $\mathrm{CO}_{2}$ concentration $(5 \% \mathrm{v} / \mathrm{v})$. For transfection experiments, $17 \times 10^{3}$ cells $/ \mathrm{cm}^{2}$ cells were plated onto glass coverslips; $1 \mu \mathrm{g}$ for each plasmid, previously amplified and purified from bacterial strains (HiSpeed Plasmid Maxi Kit, QIAGEN, Italy), was transfected with Arrest-In ${ }^{\mathrm{TM}}$ (Open Biosystems, Celbio, Italy) two days after plating.

Wistar rats (Charles River Laboratories, USA) were maintained in the Animal Research Facility of the Department of Biomedical Sciences (University of Padova) under standard environmental conditions. All the experiments dealing with animals have been approved by the Institutional Ethical Committee (CEASA) of the University of Padova. Primary neurons were dissociated with papain from freshly dissected E18 rat embryos hippocampi (E1 being the day when vaginal plug was found; Berry, 1970). Glia was reduced by pre-plating, and hippocampal neurons were suspended in DMEM with GlutaMAX-1, supplemented with $10 \%$ FBS, $1 \mathrm{u} / \mathrm{ml}$ penicillin, and $1 \mu \mathrm{g} / \mathrm{ml}$ streptomycin. About $34 \times 10^{3}$ neurons $/ \mathrm{cm}^{2}$ were plated onto glass coverslips (previously coated with $10 \mu \mathrm{g} / \mathrm{ml}$ poly-L-lysine) in L15 medium supplemented with $5 \% \mathrm{FBS}$ and incubated at $37^{\circ} \mathrm{C}$ and $5 \% \mathrm{CO}_{2}$ for $90 \mathrm{~min}$. L15 was then substituted with Neurobasal ${ }^{\mathrm{TM}}$ Medium added with $1 \%$ FBS, $1 \%$ GlutaMAX ${ }^{\mathrm{TM}}-1$, and 2\% B-27. Three days after dissociation, neurons were maintained in Neurobasal ${ }^{\mathrm{TM}}$ Medium supplemented with 2\% B-27 (Brewer, 1997; Vassanelli and Fromherz, 1997). One microgram of each plasmid was transfected into 6 days in vitro (DIV) neurons by means of Lipofectamine $^{\mathrm{TM}}$ 2000. CHO-K1 and neurons culture and transfection reagents, if not otherwise indicated, were purchased from Invitrogen.

\section{CELLS FIXATION AND LABELING}

One day after transfection, $\mathrm{CHO}-\mathrm{K} 1$ and hippocampal neurons were fixed with $10 \%$ formaline (Sigma-Aldrich) and washed with PBS, pH 7.4 (in mM: $137.0 \mathrm{NaCl}, 2.7 \mathrm{KCl}, 10.0 \mathrm{Na}_{2} \mathrm{HPO}_{4}$, $2.0 \mathrm{KH}_{2} \mathrm{PO}_{4}$ ). For long-term transfections of neurons, cells were fixed 9 days after transfection (i.e., at 15 DIV). For antibody labeling, cells were permeabilized with $0.1 \%$ Triton X-100 (Sigma-Aldrich) in PBS at room temperature for $20 \mathrm{~min}$, washed with $0.1 \%$ Tween-20 (Sigma-Aldrich) in PBS, and incubated for $30 \mathrm{~min}$ with $1 \%$ BSA (Sigma-Aldrich) in PBS. A primary monoclonal antibody against the $\mathrm{Na}_{\mathrm{v}} 1.2 \propto$ subunit intracellular C-terminus (Research Diagnostic, Fitzgerald, GA, USA) was added overnight at $4^{\circ} \mathrm{C}(2.0 \mu \mathrm{g} / \mathrm{ml})$ and visualized by using 1:300 anti-mouse IgG Alexa Fluor 568 (Invitrogen) after washing with $0.1 \%$ Tween-20 and incubating with $1 \%$ BSA. Neuronal endogenous $\beta 2$ and wild-type subunit expressed in $\mathrm{CHO}-\mathrm{K} 1$ were immunolabeled with $2 \mu \mathrm{g} / \mathrm{ml}$ polyclonal primary antibody (ASC007, Alomone Labs, Israel) with intracellular C-terminal epitope (Kaplan et al., 2001) and 1:300 anti-rabbit IgG Alexa Fluor 
514 (Invitrogen). Neuronal MAP2 protein was stained with polyclonal primary antibody (PRB-547C, Covance) and 1:300 antirabbit IgG Alexa Fluor 488 (Invitrogen). Neurofilaments $\mathrm{H}$ were immunolabeled with primary monoclonal antibody (SMI-31R, Covance) and 1:300 anti-mouse IgG Alexa Fluor 488 (Invitrogen). Actin was labeled with Alexa Fluor 568 phalloidin (Invitrogen). For FM staining, non-fixed cells were visualized after $1 \mathrm{~min}$ staining at $4^{\circ} \mathrm{C}$ with $5 \mu \mathrm{g} / \mathrm{ml} \mathrm{FM}{ }^{\circledR} 1-43$ Lipophilic Styryl Dye in HBSS (Invitrogen) and for a maximum observation time of $5 \mathrm{~min}$ (to avoid artifacts caused by dye internalization).

\section{TIRF MICROSCOPY AND IMAGE ANALYSIS}

Epifluorescence and TIRF microscopy (Axelrod, 1981, 2001) was performed using a commercial White-Light TIRF ${ }^{\mathrm{TM}}$ apparatus mounted on a Nikon TE2000E stage and a CFl Plan Apochromat TIRF $60 x / 1.45$ oil objective with $80-200 \mathrm{~nm}$ penetration depth (Nikon Instruments, England). Emission bands: 460-500 nm for ECFP, 520-550 nm for Alexa Fluor 488, 515-555 nm for Alexa Fluor 514, and 578-632 nm for Alexa Fluor 568 and phalloidin. Images were analyzed with the ImageJ (http://rsbweb.nih.gov/ij/) and Image-Pro Plus 6.0 (MediaCybernetics, USA) softwares.

\section{Subunits localization and expression}

Intensity difference analysis. A semi-quantitative estimate of $\beta 2 \mathrm{C}$ expression in the plasma membrane was obtained from TIRF images by comparing $\beta 2 \mathrm{C}$ and FM1-43 fluorescence (hereafter indicated as $F_{\beta}$ and $F_{M}$, respectively). This intensity difference analysis procedure was previously proposed to analyze membrane expression of a genetically targeted calcium sensor (Shigetomi et al., 2011). Briefly, the analysis was performed through normalization and then subtraction of $F_{M}$ from $F_{\beta}$, under the assumption that the distribution of FM1-43 was homogenous in the plasma membrane. In this way, after subtraction from $F_{\beta}$ of signal components due to reduced membrane-to-substrate distance or excitation of non-adherent membranes by the evanescent wave, fluorescence intensity was directly related to the level of $\beta 2 \mathrm{C}$ membrane expression. For each cell, a region of interest (ROI) of $5 \times 5 \mu \mathrm{m}^{2}$ area with approximately homogeneous $\beta 2 \mathrm{C}$ and FM1-43 fluorescence was selected in the center of the cell and average intensities, $\left\langle F_{\beta}>\right.$ and $\left\langle F_{M}>\right.$, computed. After normalization of the FM1-43 image to $\left\langle F_{\beta}\right\rangle$, FM1-43 intensities were subtracted from the $\beta 2 \mathrm{C}$ image and the result plotted in pseudo-color code.

Radial $\beta 2 C$ expression profiles. The $\beta 2 \mathrm{C}$ fluorescence radial profiles in the plasma membrane of $\mathrm{CHO}-\mathrm{K} 1$ cells were measured in TIRF images along manually selected linear segments $(10 \mu \mathrm{m}$ length) crossing the cell's edge and then compared to FM143 signals. When selecting segments, care was taken to exclude lamellipodia-like structures. A border-to-center ratio was computed for each selection from a five pixels average at the border and center regions of the cell.

$\boldsymbol{\alpha}$ and $\beta 2 C$ co-expressing cells. In $\alpha$ and $\beta 2 \mathrm{C}$ co-expression studies, the expression level of $\mathrm{Na}_{\mathrm{v}} 1.2 \alpha$ subunit in the plasma membrane was estimated from TIRF images of immunolabeled cells. Two parameters were extracted: a background noise, $N$, and a signal value, $S . N$ was defined as the average fluorescence intensity of 10 ROIs $\left(3 \times 3 \mu \mathrm{m}^{2}\right.$ each $)$ in non-transfected cells; $S$ was the average intensity of 10 ROIs in the transfected cell. $\mathrm{Na}_{\mathrm{v}} 1.2$ expression was then reported in arbitrary units (AU) and represented the signal-to-noise ratio $R=(S-N) / N$. An identical signal processing criterion was used for evaluation of $\beta 2 \mathrm{C}$ expression in these experiments.

Cellular processes. Lengths of filopodia-like processes were measured with ImageJ software in CHO-K1 cells expressing $\beta 2 \mathrm{C}$ or co-expressing $\alpha$ and $\beta 2 \mathrm{C}$ and compared with mocktransfected cells stained with phalloidin. Processes were then divided in 3 groups (with length $<4 \mu \mathrm{m}, 4 / 8 \mu \mathrm{m},>8 \mu \mathrm{m}$ ) and frequency reported as percentage. In neurons, filopodia-like structures were counted manually on a $20 \mu \mathrm{m}$ long arbitrary selection of the dendritic tree of each neuron. A quantitative estimate of neuronal arborization was obtained by defining a branching area index as the ratio between the area occupied by branches and the total imaged area (excluding somatas). For this analysis, raw images were acquired in standard epifluorescence by a 2 Mpixel CCD camera DS-2MBWc (Nikon Instruments) and subsequently filtered with a HighGauss and Median filter.

\section{WHOLE-CELL VOLTAGE-CLAMP}

Whole-cell patch-clamp recordings were performed $24 \mathrm{~h}$ after transfection using an Axopatch 200B amplifier (Molecular Devices, USA). The voltage protocol for steady-state activation consisted of test pulses of $60 \mathrm{~ms}$ duration with increasing amplitude ( $5 \mathrm{mV}$ step) starting from a $-90 \mathrm{mV}$ holding potential. Current transients due to passive RC pipette-membrane components and leakage were subtracted using a $\mathrm{P} / 4$ protocol. The membrane sodium conductance was computed from the applied voltage, corrected for the access resistance to obtain the true intracellular voltage, the corresponding whole-cell current and the measured sodium reversal potential. The sodium conductance steady-state activation curve was fitted, after normalization of the conductance to its maximum value, by a Boltzmann distribution describing steady-state activation in terms of the channel gating charge, $q_{g}$, and gating voltage, $V_{g}$ (Fry et al., 2003). The specific conductance was calculated by normalizing the whole-cell sodium conductance to the membrane capacitance (which was determined offline from the $\mathrm{RC}$ current transients recorded during $\mathrm{P} / 4$ pulses through fitting by exponential functions). Pyramidal-like neurons were selected on the basis of morphological criteria for recording. Extracellular and intracellular solutions used for voltage-clamp records were, respectively (in $\mathrm{mM}$ ): $135.0 \mathrm{NaCl}, 5.4 \mathrm{KCl}, 1.0$ $\mathrm{MgCl}_{2}$, $1.8 \mathrm{CaCl}_{2}, 10.0$ glucose, $5.0 \mathrm{HEPES}$ (adjusted to $\mathrm{pH}$ 7.4 with $1 \mathrm{~N} \mathrm{NaOH}$ ); $140.0 \mathrm{KCl}, 2.0 \mathrm{MgCl}_{2}$, 5.0 EGTA, 5.0 HEPES (adjusted to $\mathrm{pH} 7.3$ with $1 \mathrm{~N} \mathrm{KOH}$ ). Potassium channels blockers (20 mM TEA and $200 \mu \mathrm{M}$ 4-AP; Sigma-Aldrich) were included in the pipette solution. Neurons showing residual A-type fast inactivating potassium currents were not considered. Pipettes resistances were 2-3 M $\Omega$ in extracellular solution. Recordings showing non-negligible space-clamp artifacts and series access resistances larger than $15 \mathrm{M} \Omega$ were discarded from analysis. 


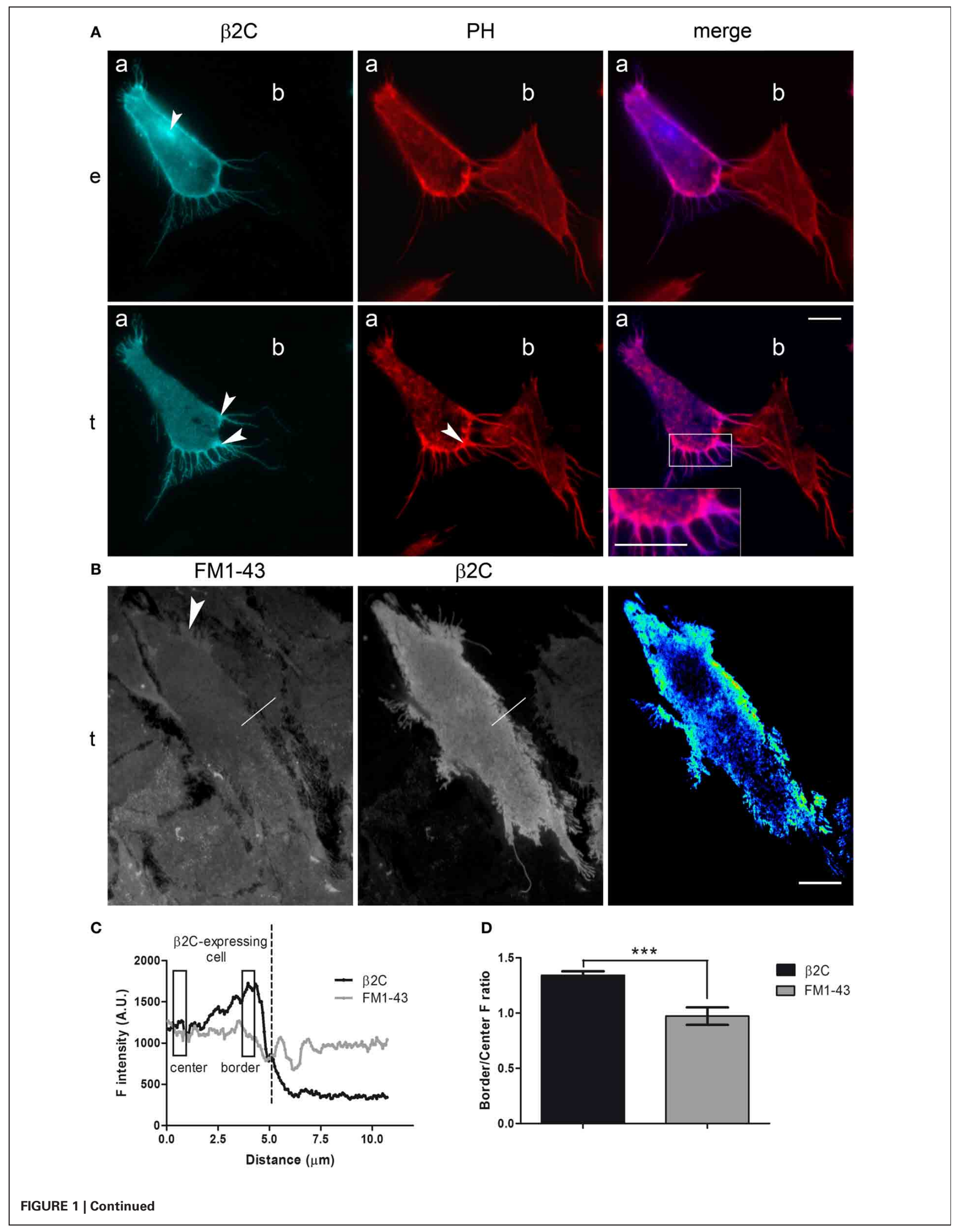


FIGURE 1 | $\mathbf{\beta 2 C}$ distribution pattern in $\mathbf{C H O}-\mathbf{K} \mathbf{1}$ cells. (A) Fluorescence microscopy micrograph (epifluorescence, $e$, and TIRF, $t$ ) showing a representative $\mathrm{CHO}-\mathrm{K} 1$ cell expressing $\beta 2 \mathrm{C}$ (a) and a non-expressing cell $(\boldsymbol{b})$ in its proximity. Phalloidin staining of F-actin in the two cells $(\mathrm{PH})$ is visible together with the merged image of $\beta 2 \mathrm{C}$ and $\mathrm{PH}$ channels. $32 \mathrm{C}$ channel: white arrows point in $e$ to a perinuclear region of subunit retention and in $t$ to lamellipodia- and filopodia-like structures with enhanced fluorescence. $\mathrm{PH}$ channel: the white arrow indicates F-actin accumulation in membrane processes of cell (a). Merge: note the blow-up showing correspondence between F-actin and $\beta 2 \mathrm{C}$ localization. (B) TIRF image with FM1-43 stained cells and some of them expressing $\beta 2 \mathrm{C}$ (left, FM1-43 channel; middle, $\beta 2 \mathrm{C}$ channel). The white arrow in the FM1-43 channel points to a typical lamellipodia-like process with higher fluorescence. Superimposed to both FM1-43 and $\beta 2 \mathrm{C}$ channels is one $10 \mu \mathrm{m}$ long linear selection crossing the cell edge (white segment) whose fluorescence intensity profile is plotted in (C) (right) Pseudo-color image obtained by intensity difference analysis of the cell in the center (signal intensity increases from cold to warm colors). Here, the higher intensity in lamellipodia-like processes and at the cell periphery suggests $\beta 2 \mathrm{C}$ accumulation in these regions. Scale bars (A,B): $10 \mu \mathrm{m}$. (C) Fluorescence intensity profiles of $\beta 2 \mathrm{C}$ (black) and FM1-43 (gray) signals along the linear selection shown in (B). FM1-43 and $\mathrm{B2C}$ signal baselines were juxtaposed for easier comparison. $\mathrm{B2} \mathrm{C}$ fluorescence rose from center to periphery reaching a maximum at the cell border, thus dropping in correspondence of the cell edge. FM1-43 fluorescence was relatively constant until the cell edge, and then it rippled because the selection was intercepting a neighboring FM-43 stained cell (not expressing $\beta 2 \mathrm{C}$ ). (D) Comparison of $\beta 2 \mathrm{C}$ and FM1-43 border-to-center ratios. Representative center and border regions considered for analysis are indicated by rectangles in (C). For each out of 8 different cells, the average of ratios in 10 selections was considered for comparison confirming a preferential localization of $\beta 2 \mathrm{C}$ at the cell border ( $\beta 2 \mathrm{C}$ : $1.34 \pm 0.11$; FM1-43: $0.97 \pm 0.08, n=8$, *** $p<0.0001$. Data expressed as mean \pm SEM).

\section{STATISTICAL ANALYSIS}

Statistical analysis and fitting was done using GraphPad Prism (GraphPad Software). Comparisons between data groups were performed using Student's $t$-tests and expressed as mean \pm SEM, with $p<0.05$ as criterion for significance. Fitting of the sodium channel activation curve by a Boltzman distribution was obtained by non-linear regression and forcing the relative conductance $\left(G_{\mathrm{M}} / G_{0}\right)$ to one in correspondence of the highest depolarizing voltage.

\section{RESULTS}

\section{ACCUMULATES AT THE PERIPHERY AND IN MEMBRANE PROCESSES OF CHO-K1 CELLS}

$\beta 2$ expression was firstly investigated in $\mathrm{CHO}-\mathrm{K} 1$ cells. Indeed, as native sodium channels are nearly absent in this cell line (Lalik et al., 1993), the system was offering the opportunity to study $\beta 2$ in a context where it is not involved in the formation of channel complexes. A $\beta 2$-ECFP chimera $(\beta 2 \mathrm{C})$ was engineered (see Materials and Methods) to observe the subunit subcellular distribution by fluorescence microscopy at high spatial resolution. A representative cell expressing $\beta 2 \mathrm{C}$ is shown in Figure $1 \mathrm{~A}$ as it appears under epifluorescence and TIRF microscopy (panel $e$ and $t$ ). Overall, the subunit displays its normal preferential localization to the plasma membrane (Isom et al., 1995) with the exception of a few intracellular perinuclear spots, visible in epifluorescence, that were likely caused by accumulation in intracellular membranes as already reported by Zimmer et al. (2002) in HEK293 cells. In the TIRF image, a higher $\beta 2 \mathrm{C}$ fluorescence intensity is found at the cell periphery and, particularly, in membrane processes. As evidenced by phalloidin labeling of F-actin $(\mathrm{PH})$, there was a good correspondence between these high fluorescence intensity regions and sites rich of actin filaments, typically indicating nascent adhesions and membrane protrusions (Parsons et al., 2010). To assess whether the increase of the $\beta 2 \mathrm{C}$ signal in these regions was indeed due to higher protein membrane expression and not to unrelated phenomena (i.e., reduced membrane-substrate distance or excitation of both adherent and non-adherent membrane by the evanescent wave), we compared $\beta 2 \mathrm{C}$ fluorescence with that of FM1-43, a dye which integrates and distributes homogeneously in the cell membrane (Figure 1B). FM1-43 fluorescence was homogeneous in the cell body but, similarly to $\beta 2 \mathrm{C}$, also enhanced in correspondence of filopodiaand lamellipodia-like structures. We concluded that the higher $\beta 2 \mathrm{C}$ signal at the periphery of cell adhesion and in processes was due, at least in part, to tighter adhesion or spurious excitation of non-adherent membranes. Thus, the signal component directly related to a higher level of membrane protein expression was identified by first normalizing and then subtracting the FM1-43 fluorescence from the $\beta 2 \mathrm{C}$ channel through a quantitative intensity difference analysis (see Materials and Methods). The resulting image showing regions of $\beta 2 \mathrm{C}$ accumulation in a representative cell is visible in Figure 1B. For easy of visualization, intensities are displayed in pseudo-color. Prevalence of warm colors in lamellipodia- and filopodia-like processes indicates preferential localization of $\beta 2 \mathrm{C}$ in the adherent membrane of these structures. Overall, all observed $\beta 2 \mathrm{C}$ expressing cells were showing a similar pattern. Alternatively, to analyze the pattern of $\beta 2 \mathrm{C}$ distribution and particularly outside lamellipodia-like processes, fluorescence was measured along selections perpendicular to the membrane's edge (10 $\mu \mathrm{m}$ length) that were crossing the cell border (Figure 1B). $\beta 2 \mathrm{C}$ but not FM1-43 intensity profiles typically raised in correspondence of the cell periphery (Figure 1C) and averages of periphery-to-center ratios showed a significant $34 \%$ increase for $\beta 2 \mathrm{C}$ compared to FM1-43 (Figure 1D). Taken together, these results indicated that $\beta 2 \mathrm{C}$ was preferentially localized in membrane processes and, overall, at the periphery of the adherent membrane in $\mathrm{CHO}-\mathrm{K} 1$, a pattern that is typically observed in case of proteins involved in cell adhesion (Parsons et al., 2010).

\section{NA $1.2 \alpha$ SUBUNIT CAUSES INTRACELLULAR SEQUESTRATION OF $\beta 2$ AND REDUCES FORMATION OF MEMBRANE PROCESSES}

Since $\beta 2$ is recognized as an accessory subunit of VGSCs, its subcellular distribution and effect on $\mathrm{CHO}-\mathrm{K} 1$ morphology were also investigated when co-expressed with the $\mathrm{Na}_{\mathrm{v}} 1.2$ main poreforming $\alpha$ subunit. This $\mathrm{Na}_{\mathrm{v}}$ isoform was demonstrated to associate with $\beta 2$ in the rat hippocampus and other brain regions (Gong et al., 1999), thus representing a suitable physiological binding target of the accessory subunit. When co-expressed with $\mathrm{Na}_{\mathrm{v}} 1.2$ in this non-neuronal cell line, $\beta 2 \mathrm{C}$ was mainly retained in the perinuclear region, in contrast to the dominant membrane targeting that was observed when the subunit was 


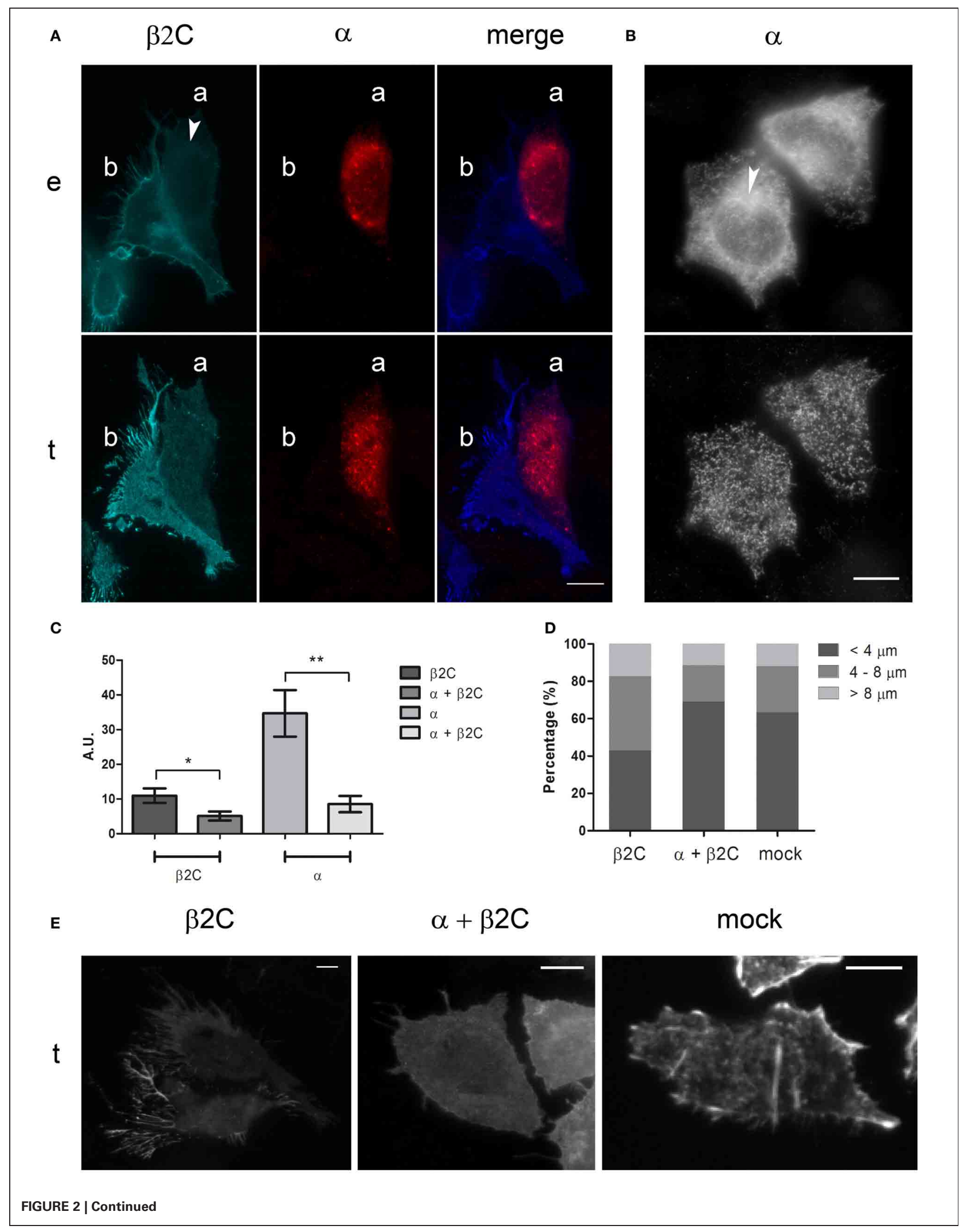


FIGURE 2 | $\mathrm{Na}_{\mathrm{v}} 1.2 \alpha$ subunit inhibits membrane processes formation by causing intracellular sequestration of $\mathbf{\beta 2 C}$. (A) Epifluorescence (e) and TIRF $(t)$ micrographs of two representative cells co-expressing $\beta 2 C$ and $\alpha$ (cell $\boldsymbol{a}$ ) or expressing $\beta 2 \mathrm{C}$ alone (cell $\boldsymbol{b}$ ). $\alpha$ was antibody labeled. From left to right: $\beta 2 \mathrm{C}$ channel (cyan), a channel (red), merged image. White arrow indicates $\beta 2 \mathrm{C}$ intracellular retention around the nucleus. Note the lower level of fluorescence in cell $(\boldsymbol{a})$ with respect to $(\boldsymbol{b})$ in the $\beta 2 \mathrm{C}$ channel and the intracellular co-localization in (a) of the two subunits in the merged image, hinting to a subunit as the cause of reduced membrane expression of $\beta 2 \mathrm{C}$. Most notably, membrane processes appear to be reduced in (a) with respect to (b). (B) Micrographs of $\alpha$ transfected cells ( $e$ and $t$ as in $\mathbf{A}$ ). Despite perinuclear retention (arrow in e), a subunit targeting to the plasmatic membrane remains significant $(t)$. Scale bars $(\mathbf{A}, \mathbf{B}): 10 \mu \mathrm{m}$. (C) Averaged TIRF signals of cells expressing $\beta 2 \mathrm{C}$ or co-expressing $\alpha$ and $\beta 2 \mathrm{C}$, normalized to basal noise and expressed in arbitrary units (AU). $\beta 2 \mathrm{C}$ channel: $\beta 2 \mathrm{C}$ cells $(10.98 \pm 2.07 ; n=10), \alpha+\beta 2 \mathrm{C}$ cells $(5.11 \pm 1.29 ; n=10)$. $\alpha$ channel: $\alpha$ cells $(34.69 \pm 6.70 ; n=10), \alpha+\beta 2 C$ cells $(8.53 \pm 2.35 ; n=10)$. Data expressed as mean $\pm \mathrm{SEM}$. A significant decrease $\left(^{*} p=0.0271\right)$ of $\beta 2 C$ targeting to the plasmatic membrane is found when $\alpha$ is co-expressed. Similarly, a significant decrease $\left({ }^{* *} p=0.0017\right)$ of $\alpha$ targeting to the plasmatic membrane is observed in case of $\beta 2 \mathrm{C}$ co-expression. (D) Percentage of filopodia-like structures with length $<4 \mu \mathrm{m}, 4 / 8 \mu \mathrm{m},>8 \mu \mathrm{m}$ as counted in $20 \mathrm{CHO}-\mathrm{K} 1$ cells expressing $\beta 2 C(n=247), \alpha$ and $\beta 2 C(n=184)$, or mock $(n=167)$ from at least three independent transfections. Note the increased percentage of filopodia-like processes with length $>4 \mu \mathrm{m}$ in $\beta 2 \mathrm{C}$ expressing cells. (E) Representative cells expressing $\beta 2 C$ and $\alpha+\beta 2 C$ ( $\beta 2 C$ channel) and mock (phalloidin staining) from the populations analyzed in (D). Scale bars: $10 \mu \mathrm{m}$. expressed alone (Figures 2A,C). Considering the similar distribution pattern of $\alpha$ and $\beta 2 \mathrm{C}$ in the merged image of Figure 2A, we can speculate that $\mathrm{Na}_{\mathrm{v}} 1.2$ was causing $\beta 2 \mathrm{C}$ retention in endomembranes through formation of channel complexes lacking appropriate membrane targeting signals. A similar pattern was found when co-expressing $\alpha$ and the wild-type $\beta 2$, thus excluding the possibility of a chimera-specific effect (not shown). The $\alpha$ subunit, when expressed alone, showed a partial accumulation in perinuclear structures, although maintaining a certain degree of membrane expression (Figures 2B,C). Statistical analysis over a population of co-expressing and non-co-expressing cells demonstrated a significant 2 -fold decrease of the $32 \mathrm{C}$ signal in the plasma membrane in case of $\alpha-\beta 2 \mathrm{C}$ co-expression. Similarly, a significant 4 -fold decrease of the $\alpha$ subunit signal in the plasmatic membrane was found when $\alpha$ and $\beta 2 \mathrm{C}$ were coexpressed (Figure 2C). Interestingly, when analyzing the effect of co-expression on membrane processes, we found that the percentage of long (more than $4 \mu \mathrm{m}$ ) filopodia-like structures was significantly higher in $\beta 2 \mathrm{C}$ transfected cells with respect to $\alpha$ and $\beta 2 \mathrm{C}$ co-expression and mock conditions (Figures 2D,E). These observations indicated that $\beta 2 \mathrm{C}$ expression promotes outgrowth of filopodia-like cellular processes, a process that requires targeting of the subunit to the membrane. To investigate the effect of $\beta 2 C$ expression on functional sodium channels, sodium currents were measured in CHO-K1 cells co-transfected with the $\alpha$ and $\beta 2 C$ subunits and compared to cells expressing $\alpha$ alone. Overall, a tendency, albeit not significant, to a decrease of specific sodium conductance was observed in $\alpha$ and $\beta 2 \mathrm{C}$ co-expressing cells (Figure 3A). Apparently, despite reducing the membrane targeting of the $\alpha$ subunit (Figure 2C), $\beta 2 \mathrm{C}$ expression did not significantly affect the membrane targeting of mature functional channels capable to conduct ionic sodium currents. Furthermore, the voltage-dependence of activation in the two conditions only displayed slight differences, which plays against a dominant role of $\beta 2 \mathrm{C}$ in the formation of sodium channel complexes and their gating modulation in these cells (Figure 3B).

\section{B2 PROMOTES FILOPODIA-LIKE PROCESSES OUTGROWTH AND DENDRITIC BRANCHING IN DEVELOPING RAT HIPPOCAMPAL NEURONS}

Taking the cue from the changes in membrane morphology observed in $\mathrm{CHO}-\mathrm{K} 1$ and to gain insights into the functional role of $\beta 2$ in neuronal cells, we studied the effect of $\beta 2 \mathrm{C}$ overexpression

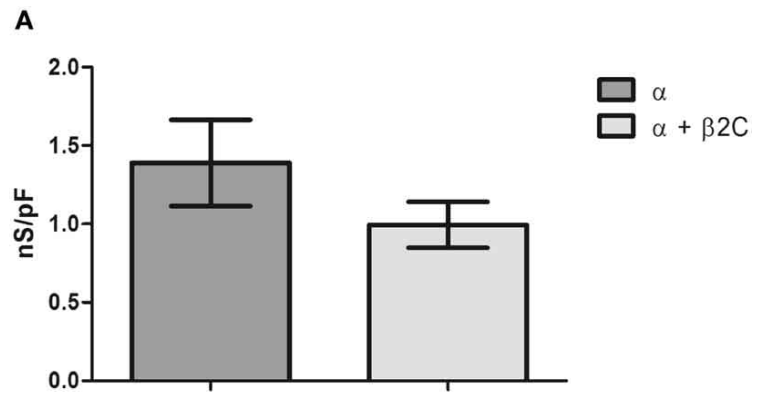

B

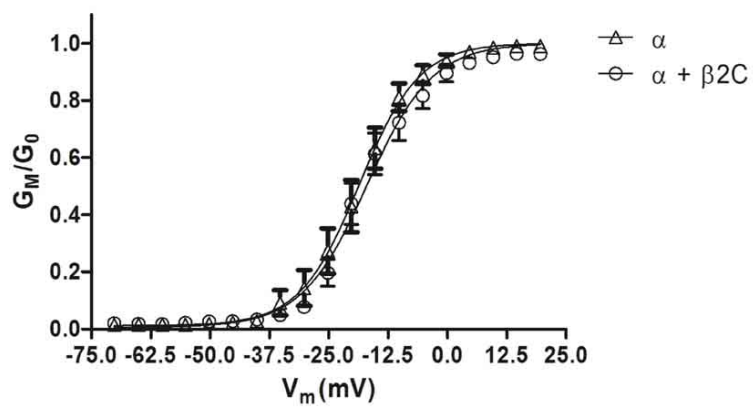

FIGURE 3 | Nav 1.2 conductance in CHO-K1 cells is slightly affected by B2C co-expression. (A) Whole-cell peak sodium conductance, normalized to membrane capacitance, as measured in $\mathrm{CHO}-\mathrm{K} 1$ cells expressing $\mathrm{Na}_{\mathrm{v}} 1.2$ alone or co-expressing $\mathrm{Na}_{\mathrm{v}} 1.2$ and $\beta 2 \mathrm{C} 24 \mathrm{~h}$ after transfection. The voltage-clamp protocol consisted of a $60 \mathrm{~ms}$ test pulse to $+10 \mathrm{mV}$ starting from a $-90 \mathrm{mV}$ holding potential. A slight, albeit not significant $(p=0.2062)$, decrease of average conductance was observed in co-transfected cells $(\alpha=1.39 \pm 0.27 \mathrm{nS} / \mathrm{pF}, n=15 . \alpha+\beta 2 \mathrm{C}=0.99 \pm 0.14 \mathrm{nS} / \mathrm{pF}, n=16)$. Data are expressed as mean \pm SEM. (B) Voltage-dependence of sodium channels activation in the same $\alpha$ (triangles) and $\alpha+\beta 2 C$ (circles) neurons as in (A). $G_{M} / G_{0}$ is the relative conductance (actual conductance divided by the maximum conductance) and $V_{m}$ the intracellular voltage. Data were fitted by Boltzmann distributions (continuous lines) showing slight significant differences $(p=0.0051)$ between the two conditions in terms of half-voltage $\left(\beta 2 \mathrm{C}, V_{0.5}=-18.56 \pm 0.14 \mathrm{mV} ; \alpha+\beta 2 \mathrm{C},-16.94 \pm 0.53 \mathrm{mV}\right.$ ) and slope $(\beta 2 \mathrm{C}, s=6.29 \pm 0.12 \mathrm{mV} / \mathrm{e}$-fold conductance change; $\alpha+\beta 2 \mathrm{C}$, $s=6.89 \pm 0.45 \mathrm{mV} / \mathrm{e}$-fold).

in rat hippocampal neurons in culture. Embryonic hippocampal neurons at 18 days of gestation were maintained in culture and transfected at 6 DIV with $\beta 2 \mathrm{C}$. At this stage of development, indeed, we usually observed the first appearance of sodium 
currents in whole-cell electrophysiological recordings, which was signaling the expression onset of mature sodium channels in the plasma membrane. Similarly to $\mathrm{CHO}-\mathrm{K} 1$ cells, $\beta 2 \mathrm{C}$ localized mainly in the plasma membrane, despite some perinuclear clustering was also present. Preferential targeting to the cell membrane was confirmed by TIRF microscopy, with the chimera displaying a widespread distribution both in the soma and neuronal branches (Figure 4A). Since from early stages of expression (e.g., 1 or 2 days from transfection), $\beta 2 \mathrm{C}$ was causing the dynamic appearance of a large number of filopodia-like processes emerging from the branching tree, an effect that was not observed in control neurons transfected with ECFP only (Figure 4B). These newly emerging processes appeared to be similar in morphology and dynamics to those typically observed during development of native hippocampal neurons and that have been suggested as putative precursors of dendritic spines (Ziv and Smith, 1996). Filopodia-like outgrowth led to generation of a highly branched arborization tree. The branching area index (see Materials and Methods) evaluated at the same stage of development, displayed a significant 2-folds increase in $\beta 2 \mathrm{C}$ neurons (Figure 4C), demonstrating that appearance of $\beta 2 \mathrm{C}$-dependent filopodia-like processes was indeed leading to significant expansion of the arborization tree.

Interestingly, we observed that the genesis of filopodia-like structures and enhanced arborization was specific for the dendritic tree. MAP2 and phalloidin staining of $\beta 2 \mathrm{C}$ expressing 7 DIV neurons evidenced that dendrites undergo extensive branching with respect to ECFP transfected controls (Figures 5A,B). Even after 9 days from $\beta 2 \mathrm{C}$ transfection (15 DIV), neurons were maintaining an expanded dendritic arborization, thus suggesting that this $\beta 2 \mathrm{C}$ induced morphological change is not transient but probably conserved during neuronal development (Figure 5C). Image analysis performed on 7 DIV neurons expressing either $\beta 2 \mathrm{C}$ or ECFP, showed that the average number of emerging filopodia-like processes was about 4 -fold higher in $\beta 2 \mathrm{C}$ neurons than in ECFP controls. In addition, a significant time-dependent increase of filopodia-like processes emerged from comparison between 7DIV and 15DIV $\beta 2 \mathrm{C}$ transfected neurons (Figure 6). Although MAP2 staining already provided indication that axonal branching is not affected by $\beta 2 \mathrm{C}$ expression, we specifically investigated neurite morphology by $\mathrm{Na}_{\mathrm{v}} 1.2$ or SMI-31 labeling. Noteworthy, and in contrast to dendrites, axons did not display outgrowth of filopodia-like processes and increased arborization demonstrating that $\beta 2 \mathrm{C}$ specifically promoted dendritic branching (Figure 7). Interestingly, $\beta 2 \mathrm{C}$ overexpression did not affect $\mathrm{Na}_{\mathrm{v}} 1.2$ membrane targeting as $\beta 2 \mathrm{C}$ transfected neurons exhibited unaltered $\mathrm{Na}_{\mathrm{v}} 1.2$ sub-cellular localization, with a preferential targeting of the channel to the axon (Lou et al., 2005) (Figure 7A). Finally, we investigated whether the $\beta 2 \mathrm{C}$ membrane expression pattern could differ from that one of the native subunit in neurons. As verified by immunolabeling, $\beta 2 \mathrm{C}$, and the endogenous $\beta 2$ exhibited a similar distribution pattern localizing all over the neuronal membrane, including axon and dendrites (Figure 7B).

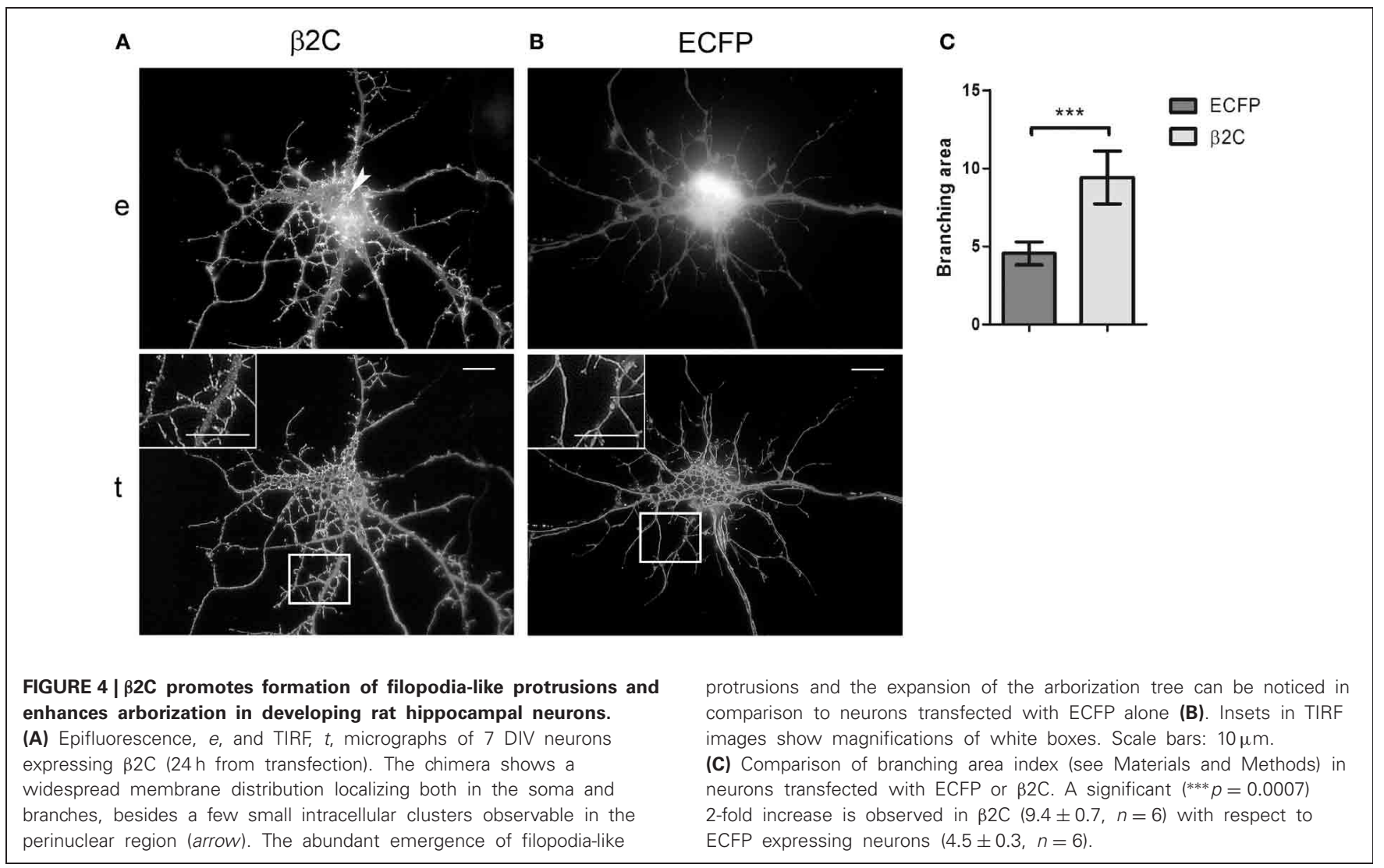


A

7DIV

t

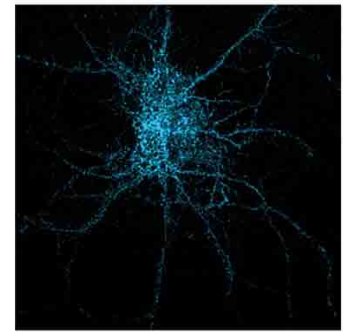

B

7DIV

e
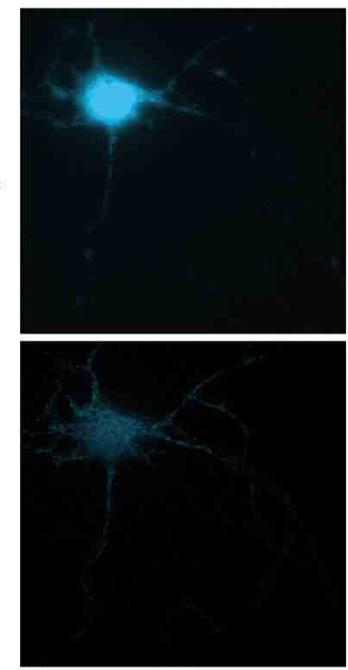

C

$\beta 2 \mathrm{C}$

15DIV

e
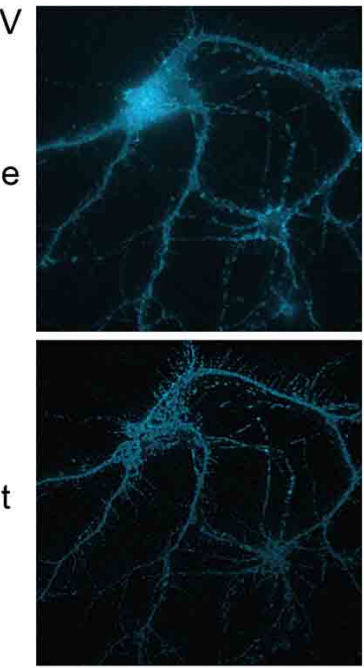

MAP2

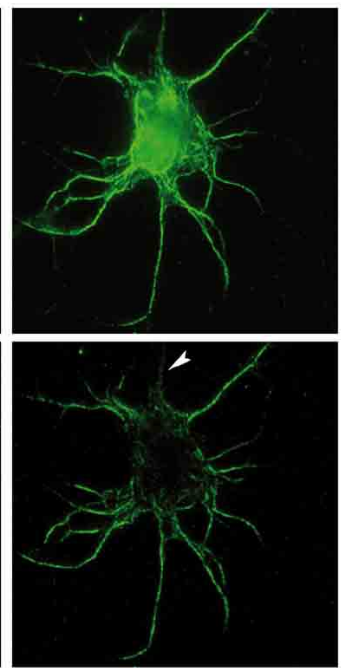

MAP2

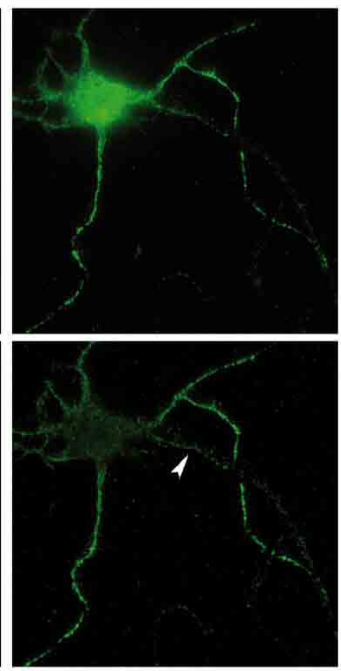

MAP2

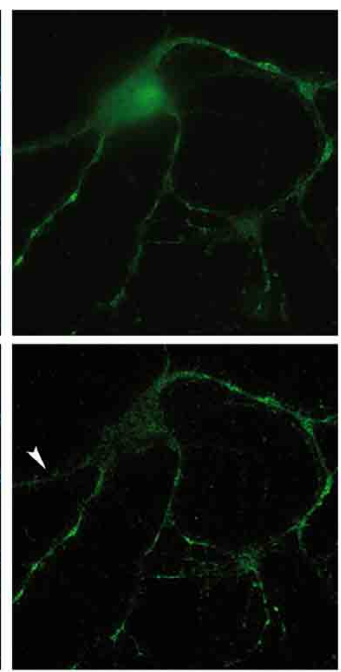

$\mathrm{PH}$

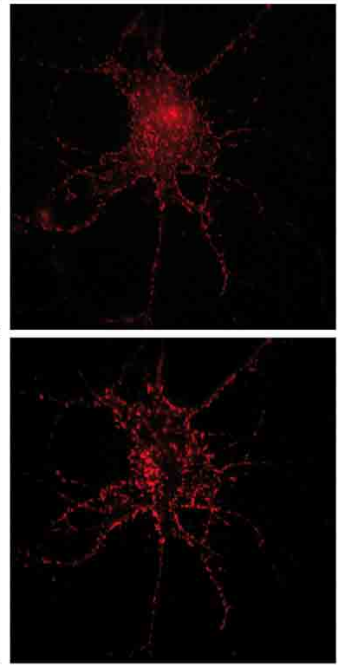

$\mathrm{PH}$

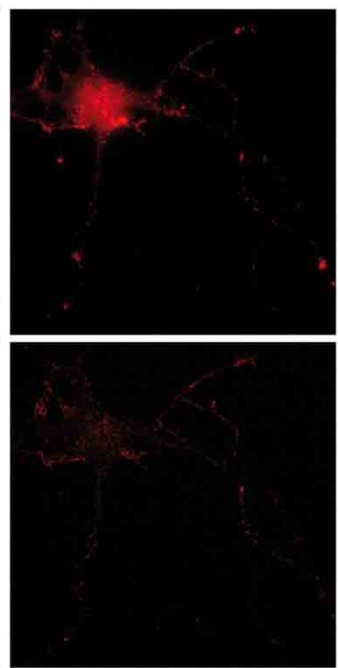

$\mathrm{PH}$

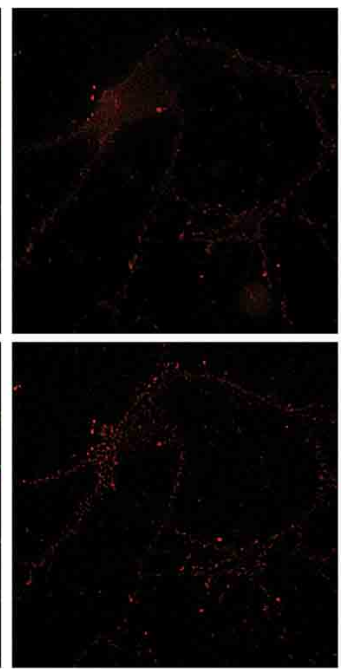

merge

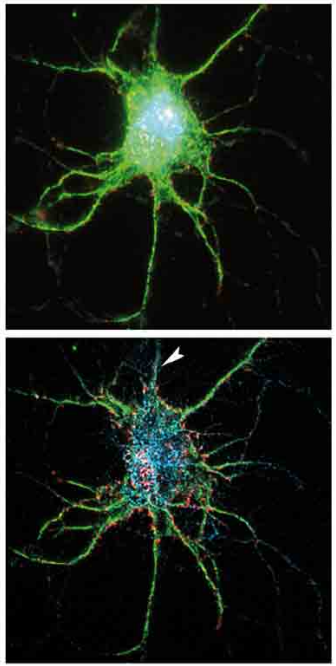

merge

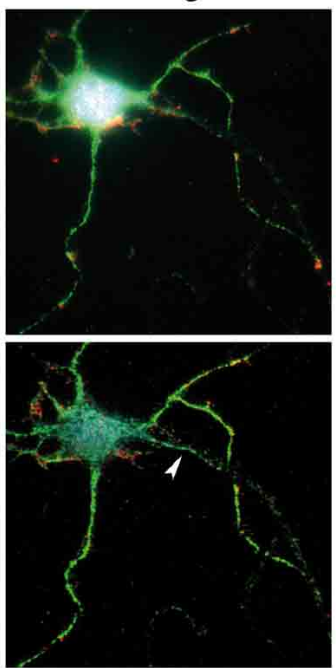

merge
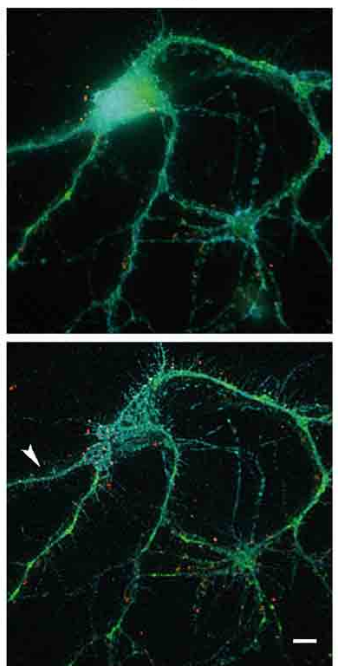
FIGURE 5 | $\beta 2 \mathrm{C}$ effect on branching is dendritic specific and is maintained in developing rat hippocampal neurons in culture. (A) Epifluorescence $(e)$ and TIRF ( $t$ ) images of a typical $\beta 2 \mathrm{C}$ expressing neuron at 7 DIV (24h from transfection) and stained for MAP2 and Phalloidin $(\mathrm{PH})$ in order to visualize dendritic processes. (B) While dendritic arborization is expanded in (A), in control neurons expressing ECFP the effect is not visible. (C) $\beta 2 \mathrm{C}$ expressing neurons at 15 DIV (i.e., 9 days from transfection) maintain enhanced dendritic arborization. (A-C): arrows point to probable axons identified by near absence of MAP2 staining. Scale bars: $10 \mu \mathrm{m}$.

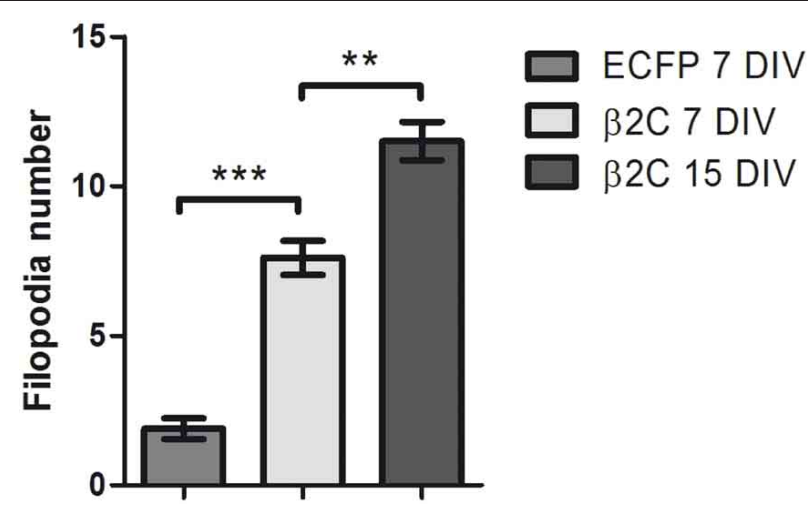

FIGURE 6 | $\beta 2 C$ expression increases the number of dendritic filopodia. The average count of filopodia-like protrusions in MAP2 stained dendrites is compared in ECFP $(1.89 \pm 0.35, n=9)$ and $\beta 2 C(7.60 \pm 0.56, n=10)$ expressing neurons at 7 DIV. A significant $(* * * p<0.0001) 4$-fold increase of filopodia-like processes is observed in $\beta 2 \mathrm{C}$ expressing cells. Furthermore, the number of processes in $\beta 2 \mathrm{C}$ expressing neurons at 15 DIV

$(11.50 \pm 0.64, n=4)$ is significantly higher $\left(^{* *} p=0.0019\right)$ with respect to 7 DIV neurons. Data expressed as mean \pm SEM

Similarly with what was found in CHO-K1 cells co-transfected with $\mathrm{Na}_{\mathrm{v}} 1.2$ and $\beta 2 \mathrm{C}$, peak sodium conductance and activation curve characteristics were not modified by $\beta 2 \mathrm{C}$ overexpression, as only a slight and non-significant shift in the hyperpolarizing direction was found in the voltage-dependence of activation (Figure 8).

\section{DISCUSSION}

$\beta$ auxiliary subunits of VGSCs are emerging as multifunctional molecules involved in modulation of sodium channels gating, in their regulation of expression and membrane targeting as well as in cell adhesion-related events such as cell migration or neurite outgrowth and fasciculation. At the root of this is structural versatility, allowing for both formation of channel complexes with $\alpha$ subunits and homo- and heterophilic interactions through extracellular cell adhesion molecule (CAM) domains (Kaczmarek, 2006; Brackenbury and Isom, 2008; Brackenbury et al., 2008a; Patino and Isom, 2010). Among auxiliary subunits, $\beta 2$ is one of the most studied and evidence has accumulated on its potential for playing heterogeneous functions in the nervous system.

It is likely that apparently unrelated functions of $\beta 2$ result from differentiated molecular mechanisms that are activated depending on cell type or developmental stage.

One of the most striking effects of $\beta 2$ expression in host cells is the enhancement of membrane processes and an increase of membrane surface as observed in Xenopus oocytes (Isom et al., 1995) and mammalian HEK293 cells (Zimmer et al., 2002).
Similarly, the auxiliary subunit could contribute to promote processes outgrowth in neurons, in association, or independently from its $\alpha$ subunit-related functions (Xiao et al., 1999). To investigate this hypothesis, we first characterized sub-cellular localization and effects on generation of membrane processes of a $\beta 2$ fluorescent chimera, $\beta 2 \mathrm{C}$, in $\mathrm{CHO}-\mathrm{K} 1$ cells, either in the presence or in the absence of $\mathrm{Na}_{\mathrm{v}} 1.2$.

\section{EFFECT OF $\beta 2$ ON THE GENERATION OF MEMBRANE PROCESSES, NAv1.2 MEMBRANE TARGETING AND GATING MODULATION IN CH0-K1 CELLS}

Fluorescence intensities of $\beta 2 \mathrm{C}$ and FM1-43, a membrane-specific lipophilic dye, were enhanced under TIRF microscopy in correspondence of the cell periphery and of lamellipodia- and filopodia-like membrane protrusions (Figures 1A,B). While a higher FM1-43 signal suggested tighter adhesion in those regions that are involved in cell spreading and migration (Mattila and Lappalainen, 2008), the option of a concomitant $\beta 2 \mathrm{C}$ protein accumulation had also to be considered. To investigate chimera accumulation, FM1-43 fluorescence was subtracted from the $\beta 2 \mathrm{C}$ signal by an intensity difference analysis, as described in Materials and Methods. As a result, $\beta 2 \mathrm{C}$ appeared to be expressed at higher levels at the cell periphery and within membrane processes (Figure 1B). A statistical analysis of $\beta 2 \mathrm{C}$ signal intensity along segments crossing the cell's edge confirmed the preferential localization of the subunit at the cell border, even outside lamellipodia-like structures that were excluded from the analysis (Figures 1C,D). Considering also that $\beta 2 \mathrm{C}$ expressing cells were displaying a clear increase of lamellipodia- and filopodia-like protrusions and that the subunit had a localization pattern similar to actin filaments (Figure 1A), the results were suggesting that $\beta 2 \mathrm{C}$ was promoting membrane adhesion and spreading in $\mathrm{CHO}-\mathrm{K} 1$ cells. Cell spreading and migration are generally thought to be mediated by filopodia and lamellipodia enriched with adhesion molecules for the extracellular matrix such as cadherins and integrins (Galbraith et al., 2007; Chioni et al., 2009; Parsons et al., 2010). $\beta 2$ could act in a similar manner, first by probing the extracellular matrix by its CAM domain, then activating intracellular signals leading to strengthened actin polymerization and processes formation to drive cell motion. At partial support to this hypothesis, it was previously shown that blockade of $\gamma$-secretase cleavage of $\beta 2$ C-terminal fragment inhibits cell migration (Kim et al., 2005), which implies that $\beta 2$ is indeed capable of signaling formation of membrane processes.

\section{MUTUAL INTRACELLULAR RETENTION OF NAv1.2 AND $\beta 2$ IN CH0-K1 CELLS}

$\mathrm{Na}_{\mathrm{v}} 1.2$ is one of the most important $\alpha$ subunit isoforms in the mammalian central nervous system (Catterall, 2000; Lai and Jan, 2006) and is highly represented in the hippocampus with 


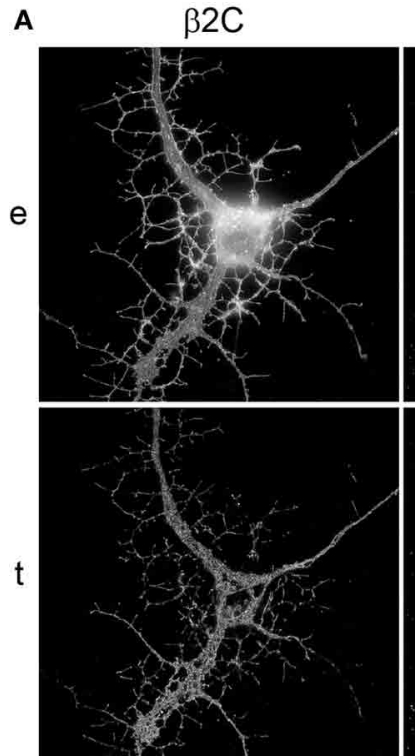

A

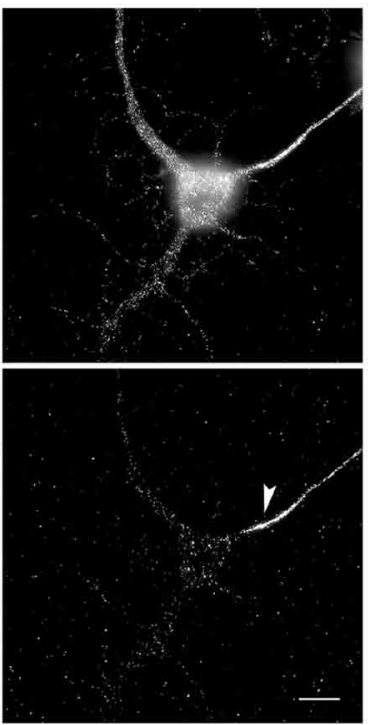

C

$\beta 2 \mathrm{C}$
B
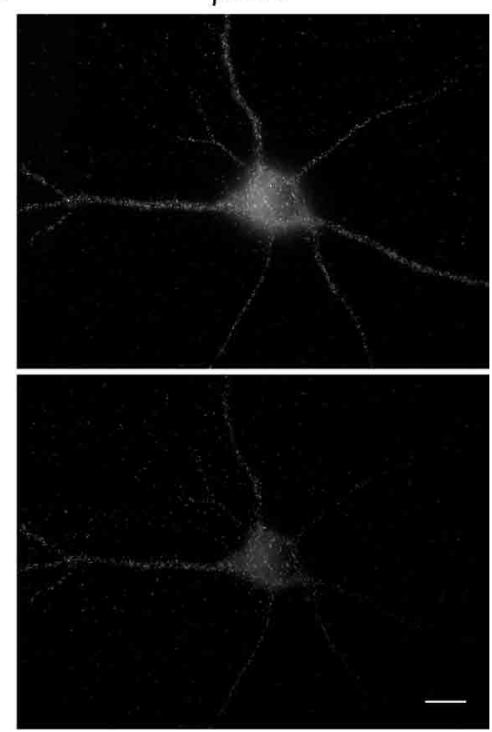

$\mathrm{PH}$ merge
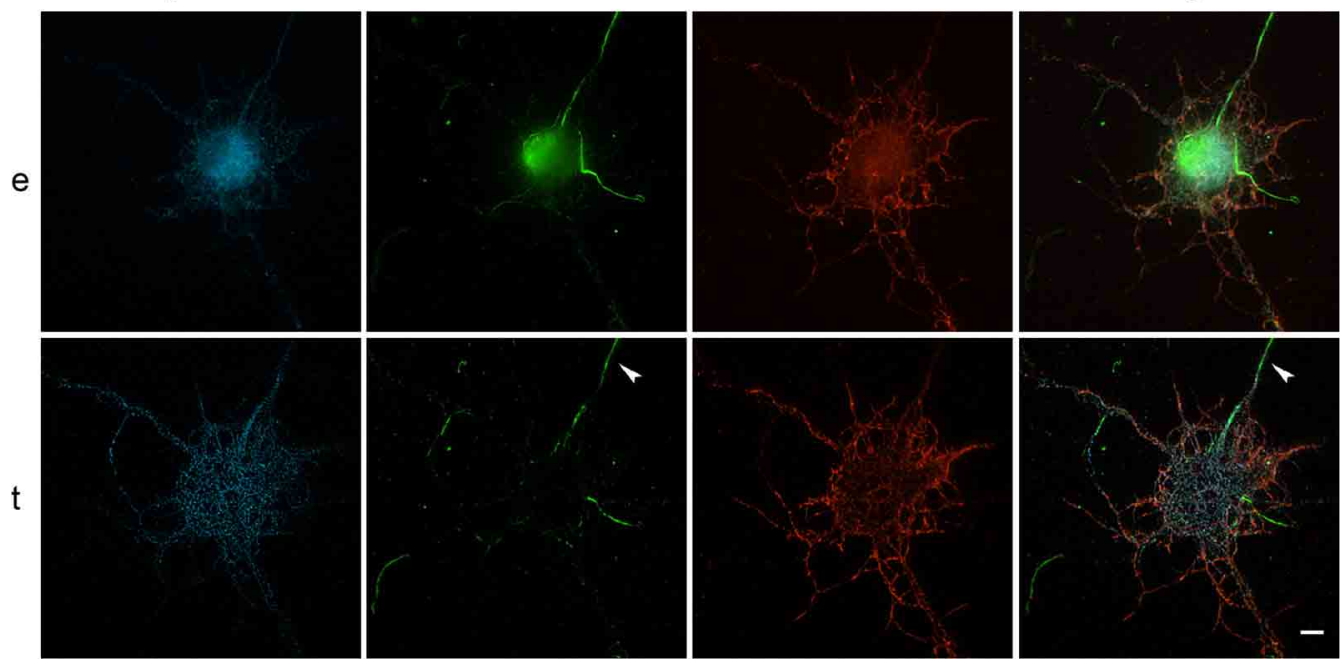

FIGURE 7 | $\beta 2 \mathrm{C}$ expression does not affect axonal branching and $\mathrm{Na}_{\mathbf{v}} \mathrm{1.2}$ targeting in developing rat hippocampal neurons.

(A) Epifluorescence (e) and TIRF ( $t$ ) images of 7 DIV neurons after $24 \mathrm{~h}$ from transfection with $\beta 2 \mathrm{C}$ and immunolabeled for $\mathrm{Na}_{v} 1.2 \alpha$ subunit. Left: $\beta 2 \mathrm{C}$ channel. Right: $\alpha$ channel. Note the staining of the axon by the anti- $\alpha$ antibody (white arrow) demonstrating that the typical axonal localization of $\mathrm{Na}_{\mathrm{v}} 1.2$ is not affected by $\beta 2 \mathrm{C}$ overexpression. Furthermore, as it can be observed in the $\beta 2 \mathrm{C}$ channel, the branching enhancement observed within the dendritic tree is not present at the axonal level. (B) 7 DIV wild-type neuron immunolabeled for the endogenous $\beta 2$ subunit. $\beta 2$, as the $\beta 2 \mathrm{C}$ chimera, shows a widespread distribution in the plasma membrane of both neuronal soma and branches. (C) 7 DIV neurons after $24 \mathrm{~h}$ from transfection with $\beta 2 \mathrm{C}$ are stained with SMI-31. Note the absence of filopodia-like structures and enhanced branching in the axon (arrow) and the correspondence of $\beta 2 \mathrm{C}$ and F-actin $(\mathrm{PH})$ signal in dendrites and their protrusions. Scale bars: $10 \mu \mathrm{m}$. a preferential localization in unmyelinated axons (Westenbroek et al., 1989; Gong et al., 1999). Since $\mathrm{Na}_{\mathrm{v}} 1.2$ has been shown to form complexes with $\beta 2$ (Schmidt and Catterall, 1987; Gong et al., 1999), we investigated the effect on membrane targeting and sodium current properties of this channel in $\beta 2 \mathrm{C} \mathrm{co-}$ expressing $\mathrm{CHO}-\mathrm{K} 1$ cells. A significant retention of $\mathrm{Na}_{\mathrm{v}} 1.2$ and $\beta 2 \mathrm{C}$ within endomembranes was observed, reminding the distribution described in developing rat brain neurons (Schmidt et al., 1985; Gong et al., 1999) (Figure 2A). $\mathrm{Na}_{\mathbf{V}} 1.2$ targeted more efficiently to the plasma membrane when expressed alone, despite a relevant intracellular retention as observed for $\mathrm{Na}_{\mathrm{v}} 1.5$ in other cell lines (Zimmer et al., 2002) (Figures 2B,C). Interestingly, measurements of whole-cell sodium conductance showed a similar degree of expression of functional channels under the two conditions (Figure 3A) and, at the gating level, we did not observe major differences in the voltage-dependence of activation (Figure 3B). Taken together, these results suggested that $\beta 2 \mathrm{C} / \mathrm{Na}_{\mathrm{v}} 1.2$ co-expression caused intracellular retention of 


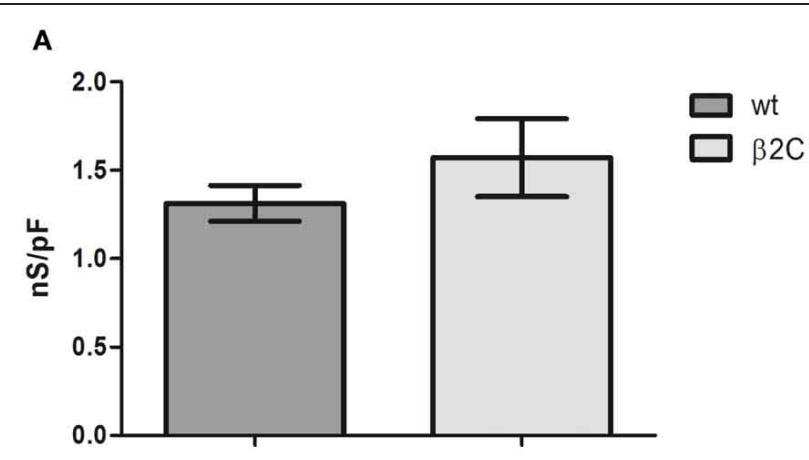

B

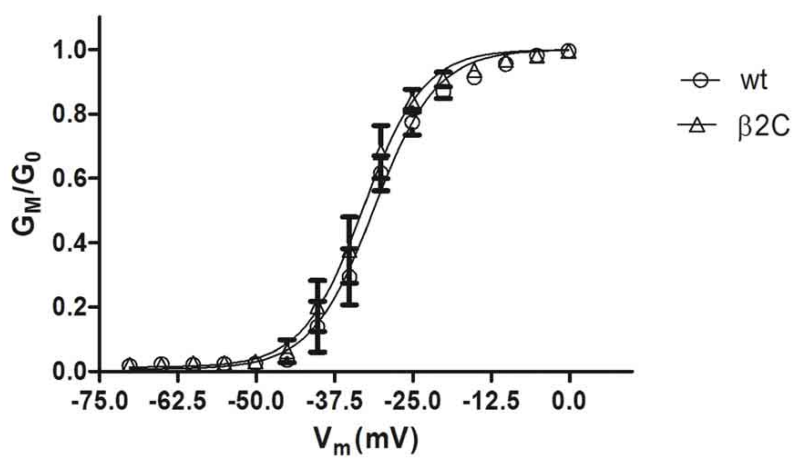

FIGURE 8 | Sodium-specific conductance and voltage-dependence of activation in $\beta 2 \mathrm{C}$ transfected rat hippocampal neurons. (A) Whole-cell peak-specific conductance in rat hippocampal neurons in culture (7 DIV). $\beta 2 \mathrm{C}, \beta 2 \mathrm{C}$ expressing neurons at $24 \mathrm{~h}$ from transfection; wt, wild-type controls; Voltage protocol, $+10 \mathrm{mV}$ test pulse starting from $-90 \mathrm{mV}$ holding potential. No significant differences $(p=0.3902)$ of specific conductance were observed in the two conditions (wt $=1.3 \pm 0.1 \mathrm{nS} / \mathrm{pF}, n=8$; $\beta 2 \mathrm{C}=1.6 \pm 0.2 \mathrm{nS} / \mathrm{pF}, n=13)$. Data are expressed as mean \pm SEM. (B) Voltage-dependence of activation in wt (circles) and $\beta 2 \mathrm{C}$ (triangles) neurons. $G_{M} / G_{0}$ indicates the relative conductance (actual conductance/maximum conductance), $V_{M}$ the intracellular voltage. Fitting by Boltzmann equations show a slight albeit significant shift in the hyperpolarizing direction in $\beta 2 \mathrm{C}$ expressing neurons $(p=0.0064)$. $\beta 2 \mathrm{C}$ $V_{0.5}=-32.95 \pm 0.31 \mathrm{mV}, s=4.81 \pm 0.26 \mathrm{mV} / \mathrm{e}$-fold conductance change, $n=13$. wt: $V_{0.5}=-31.24 \pm 0.41 \mathrm{mV}, s=5.01 \pm 0.35 \mathrm{mV} / \mathrm{e}$-fold conductance change, $n=8$.

both subunits but without significantly altering the targeting of functional channels to the membrane. Thus, we may hypothesize that, in CHO-K1 cells, conducting channels are likely formed by a subpopulation of $\alpha$ subunits that are directed to the membrane independently from $\beta 2 \mathrm{C}$ association. On the other hand, hindering of $\beta 2 \mathrm{C}$ targeting to the plasma membrane by $\mathrm{Na}_{\mathrm{v}} 1.2$ markedly reduced the appearance of cell processes (Figure 2). We concluded that $\beta 2 \mathrm{C}$ capability to promote processes outgrowth was directly related to its targeting to the cell membrane.

\section{B2 ENHANCES DENDRITIC FILOPODIA AND ARBORIZATION IN DEVELOPING RAT HIPPOCAMPAL NEURONS}

To gain insights into the subunit's role in neurons, we overexpressed $\beta 2 \mathrm{C}$ in embryonic rat hippocampal neurons developing in culture. While $\beta 2$ expression occurs in the earliest phase of neurogenesis in the rat brain and is greatly increased concomitantly with axon extension and synaptogenesis (Isom et al., 1995), its association to $\mathrm{Na}_{\mathrm{v}} 1.2$ appears only at later stages (Gong et al., 1999). Thus, it is possible that during an early developmental time window $\beta 2$ contributes mainly to neuronal wiring rather than sodium channel localization and gating modulation. Thus, we chose to transfect exogenous $\beta 2 \mathrm{C}$ in neurons at 6 DIV when dendritic and axonal outgrowth and branching are actively ongoing. As at the same stage we observed the onset of sodium current appearance in our cultures, we concomitantly assessed the effects of $\beta 2 \mathrm{C}$ on sodium channels targeting and gating. Overexpression of $\beta 2 \mathrm{C}$ led to a clear increase of filopodia-like protrusions in the dendritic tree with respect to ECFP transfected controls (Figures 4A,B). Interestingly, their morphology and dynamic appearance and disappearance closely resembled those of native dendritic filopodia (Ziv and Smith, 1996), which are thought to lead to dendrite formation (Heiman and Shaham, 2010). The number of filopodia-like processes was displaying a 4-fold increase with respect to controls (Figure 6). The $\beta 2 \mathrm{C}$-mediated induction of newly emerging filopodia led to an expanded arborization with a 2 -fold increase of branching area (Figure 4C). The effect was dendrite-specific and the axon did not display either filopodia-like protrusions or branching enhancement (Figures 5, 7). Furthermore, the expansion of the dendritic tree induced by $\beta 2 \mathrm{C}$ appeared to be potentially relevant for development as it was maintained even after 9 days from transfection (Figure 5C). Also the emergence of newly formed filopodia-like structures was increasing over time as observed in 15 DIV $\beta 2 \mathrm{C}$ expressing neurons with respect to 7DIV cells (Figure 6). In order to exclude that the aforementioned effects were produced by anomalous sub-cellular distribution of the chimera, the subcellular localization of $\beta 2 \mathrm{C}$ was compared to that one of the native $\beta 2$ subunit. In both cases the auxiliary subunit displayed a widespread distribution over the whole neuronal membrane, including soma and branches (Figure 7B). Interestingly, $\beta 2 \mathrm{C}$ overexpression did not alter the typical $\mathrm{Na}_{\mathrm{v}} 1.2$ targeting to the axon (Figure 7A). This observation was in agreement with previous work suggesting that a targeting sequence within linker II-III of the pore-forming subunit is sufficient to localize and segregate $\mathrm{Na}_{\mathrm{V}} 1.2$ channels in the axon initial segment (Garrido et al., 2003). Also, $\beta 2 \mathrm{C}$ overexpression did not affect sodium conductance levels and voltage-dependence of activation (Figure 8), suggesting that either $\alpha$ subunit alone or in association with endogenous $\beta 2$ is forming conductive sodium channels in these neurons.

In conclusion, $\beta 2$ overexpression significantly promoted the emergence of dendritic filopodia and the expansion of the dendritic tree in developing neurons while it had negligible effects on sodium channels targeting and gating modulation. The specificity of $\beta 2$ action for the dendritic tree is suggestive for a role of the subunit in the modulation of neuronal wiring in vivo. Scn2b null mice showed susceptibility to epileptic seizures (Chen et al., 2002) where abnormal dendritic development could be involved in addition to the observed negative shift in the voltagedependence of inactivation. However, no broad impairment of nervous system function was evidenced in these mice. Despite that, given its high physiological expression levels throughout 
the central nervous system, $\beta 2$ is likely to contribute to normal development. Compensatory mechanisms may exist that are activated in Scn2b null mice, such as expression of the structurally related $\beta 4$ subunit that has been also found to promote dendritic outgrowth (Miyazaki et al., 2007). Interesting is the analogy with the observed stimulation of neurite extension and fasciculation by $\beta 1$ in cerebellar granule cells (Davis et al., 2004; Brackenbury et al., 2008a), which was prevented by $\beta 2$ co-expression. Although further work will be required to investigate the hypothesis, we may speculate that the two subunits contribute to differentially promote axonal and dendritic wiring during early neuronal development, while association with $\alpha$ may downplay this function by subtracting the auxiliary subunits from their free pool at later time points.

\section{ACKNOWLEDGMENTS}

The authors would like to thank A. L. Goldin, W. A. Catterall, and T. Pozzan for providing the $\beta 2, \alpha$, and ECFP constructs, respectively. The authors are grateful to F. Filippini and C. Fasolato for critical reading of the manuscript. This work was supported by a grant of the European Commission to Stefano Vassanelli (FP5, NaChip, IST-2001-38915).

\section{REFERENCES}

Auld, V. J., Goldin, A. L., Krafte, D. S., Marshall, J., Dunn, J. M., Catterall, W. A., et al. (1988). A rat brain $\mathrm{Na}^{+}$channel $\alpha$ subunit with novel gating properties. Neuron 1, 449-461.

Axelrod, D. (1981). Cell-substrate contacts illuminated by total internal reflection fluorescence. J. Cell Biol. $89,141-145$.

Axelrod, D. (2001). Total internal reflection fluorescence microscopy in cell biology. Traffic 2, 764-774.

Berry, C. L. (1970). The effect of trypan blue on the growth of the rat embryo in vivo. J. Embryol. Exp. Morphol. 23, 213-218.

Brackenbury, W. J., Davis, T. H., Chen, C., Slat, E. A., Detrow, M. J., Dickendesher, T. L., et al. (2008a). Voltage-gated $\mathrm{Na}+$ channel betal subunit-mediated neurite outgrowth requires Fyn kinase and contributes to postnatal CNS development in vivo. J. Neurosci. 28, 3246-3256.

Brackenbury, W. J., Djamgoz, M. B., and Isom, L. L. (2008b). An emerging role for voltage-gated $\mathrm{Na}+$ channels in cellular migration: regulation of central nervous system development and potentiation of invasive cancers. Neuroscientist 14, 571-583.

Brackenbury, W. J., and Isom, L. L. (2008). Voltage-gated $\mathrm{Na}+$ channels: potential for beta subunits as therapeutic targets. Expert Opin. Ther. Targets 12, 1191-1203.

Brewer, G. (1997). Isolation and culture of adult rat hippocampal neurons. J. Neurosci. Methods 71, 143-155.

Catterall, W. A. (2000). From ionic currents to molecular mechanisms: the structure and function of voltagegated sodium channels. Neuron 26, 13-25.

Catterall, W. A., Goldin, A. L., and Waxman, S. G. (2005). International union of pharmacology. XLVII. Nomenclature and structure-function relationships of voltage-gated sodium channels. Pharmacol. Rev. 57, 397-409.

Chen, C., Bharucha, V., Chen, Y., Westenbroek, R. E., Brown, A., Malhotra, J. D., et al. (2002). Reduced sodium channel density, altered voltage dependence of inactivation, and increased susceptibility to seizures in mice lacking sodium channel beta 2-subunits. Proc. Natl. Acad. Sci. U.S.A. 99, 17072-17077.

Chen, C., Calhoun, J. D., Zhang, Y., Lopez-Santiago, L., Zhou, N., Davis, T. H., et al. (2012). Identification of the cysteine residue responsible for disulfide linkage of $\mathrm{Na}+$ channel $\alpha$ and $\beta 2$ subunits. J. Biol. Chem. 287, 39061-39069.

Chioni, A. M., Brackenbury, W. J., Calhoun, J. D., Isom, L. L., and Djamgoz, M. B. (2009). A novel adhesion molecule in human breast cancer cells: voltage-gated $\mathrm{Na}+$ channel betal subunit. Int J. Biochem. Cell Biol. 41, 1216-1227.

Davis, T. H., Chen, C., and Isom, L. L. (2004). Sodium channel betal subunits promote neurite outgrowth in cerebellar granule neurons. J. Biol. Chem. 279, 51424-51432.

Fry, M., Porter, D. M., and Maue, R. A. (2003). Adenoviral-mediated expression of functional $\mathrm{Na}+\mathrm{chan}$ nel betal subunits tagged with a yellow fluorescent protein. J. Neurosci. Res. 74, 794-800.

Galbraith, C. G., Yamada, K. M., and Galbraith, J. A. (2007). Polymerizing actin fibers position integrins primed to probe for adhesion sites. Science 315, 992-995.

Gandy, S. (2005). The role of cerebral amyloid beta accumulation in common forms of Alzheimer disease. J. Clin. Invest. 115, 1121-1129.

Garrido, J. J., Giraud, P., Carlier, E., Fernandes, F., Moussif, A., Fache, M. P., et al. (2003). A targeting motif involved in sodium channel clustering at the axonal initial segment. Science 300, 2091-2094.
Gastaldi, M., Robaglia-Schlupp, A., Massacrier, A., Planells, R., and Cau, P. (1998). mRNA coding for voltagegated sodium channel beta2 subunit in rat central nervous system: cellular distribution and changes following kainate-induced seizures. Neurosci. Lett. 249, 53-56.

Goldin, A. L., Barchi, R. L., Caldwell, J. H., Hofmann, F., Howe, J. R., Hunter, J. C., et al. (2000). Nomenclature of voltage-gated sodium channels. Neuron 28, 365-368.

Gong, B., Rhodes, K. J., Bekele-Arcuri, Z., and Trimmer, J. S. (1999). Type I and type II $\mathrm{Na}(+)$ channel alpha-subunit polypeptides exhibit distinct spatial and temporal patterning, and association with auxiliary subunits in rat brain. J. Comp Neurol. 412, 342-352.

Hartshorne, R. P., Messner, D. J., Coppersmith, J. C., and Catterall, W. A. (1982). The saxitoxin receptor of the sodium channel from rat brain. Evidence for two nonidentical beta subunits. J. Biol. Chem. 257, 13888-13891

Heiman, M. G., and Shaham, S. (2010). Twigs into branches: how a filopodium becomes a dendrite. Curr. Opin. Neurobiol. 20, 86-91.

Isom, L. L., Ragsdale, D. S., De Jongh, K. S., Westenbroek, R. E., Reber, B. F., Scheuer, T., et al. (1995). Structure and function of the beta 2 subunit of brain sodium channels, a transmembrane glycoprotein with a CAM motif. Cell 83, 433-442.

Kaczmarek, L. K. (2006). Nonconducting functions of voltage-gated ion channels. Nat. Rev. Neurosci. 7, 761-771.

Kaplan, M. R., Cho, M. H., Ullian, E. M., Isom, L. L., Levinson, S. R., and Barres, B. A. (2001). Differential control of clustering of the sodium channels $\mathrm{Na}(\mathrm{v}) 1.2$ and $\mathrm{Na}(\mathrm{v}) 1.6$ at developing CNS nodes of Ranvier. Neuron 30, 105-119.

Kim, D. Y., Carey, B. W., Wang, H., Ingano, L. A., Binshtok, A. M.,
Wertz, M. H., et al. (2007). BACE1 regulates voltage-gated sodium channels and neuronal activity. Nat. Cell Biol. 9, 755-764.

Kim, D. Y., Ingano, L. A., Carey, B. W., Pettingell, W. H., and Kovacs, D. M. (2005). Presenilin/gammasecretase-mediated cleavage of the voltage-gated sodium channel beta2-subunit regulates cell adhesion and migration. J. Biol. Chem. 280, 23251-23261.

Lai, H. C., and Jan, L. Y. (2006). The distribution and targeting of neuronal voltage-gated ion channels. Nat. Rev. Neurosci. 7, 548-562.

Lalik, P. A., Krafte, D. S., Volberg, W. A., and Ciccarelli, R. B. (1993). Characterization of endogenous sodium channel gene expressed in Chinese hamster ovary cells. Am. J. Physiol. Cell Physiol. 264, C803-C809.

Lopez-Santiago, L. F., Pertin, M., Morisod, X., Chen, C., Hong, S., Wiley, J., et al. (2006). Sodium channel b2 subunits regulate tetrodotoxin-sensitive sodium channels in small dorsal root ganglion neurons and modulate the response to pain. J. Neurosci. 16, 7984-7994.

Lou, J. Y., Laezza, F., Gerber, B. R., Xiao, M., Yamada, K. A., Hartmann, H., et al. (2005). Fibroblast growth factor 14 is an intracellular modulator of voltage-gated sodium channels. J. Physiol. 569, 179-193.

Malhotra, J. D., Kazen-Gillespie, K., Hortsch, M., and Isom, L. L. (2000). Sodium channel beta subunits mediate homophilic cell adhesion and recruit ankyrin to points of cell-cell contact. J. Biol. Chem. 275 , 11383-11388.

Mattila, P. K., and Lappalainen, P. (2008). Filopodia: molecular architecture and cellular functions. Nat. Rev. Mol. Cell Biol. 9, 446-454.

Miyazaki, H., Oyama, F., Wong, H. K., Kaneko, K., Sakurai, T., Tamaoka, A., et al. (2007). BACE1 modulates filopodia-like protrusions induced 
by sodium channel beta4 subunit. Biochem. Biophys. Res. Commun. 361, 43-48.

Morgan, K., Stevens, E. B., Shah, B., Cox, P. J., Dixon, A. K., Lee, K., et al. (2000). beta 3: an additional auxiliary subunit of the voltagesensitive sodium channel that modulates channel gating with distinct kinetics. Proc. Natl. Acad. Sci. U.S.A. 97, 2308-2313.

O'Malley, H. A., Shreiner, A. B., Chen, G. H., Huffnagle, G. B., and Isom, L. L. (2009). Loss of $\mathrm{Na}+$ channel beta2 subunits is neuroprotective in a mouse model of multiple sclerosis. Mol. Cell. Neurosci. 40, 143-155.

Parsons, J. T., Horwitz, A. R., and Schwartz, M. A. (2010). Cell adhesion: integrating cytoskeletal dynamics and cellular tension. Nat. Rev. Mol. Cell Biol. 11, 633-643.

Patino, G. A., and Isom, L. L. (2010). Electrophysiology and beyond: multiple roles of $\mathrm{Na}+$ channel $\beta$ subunits in development and disease. Neurosci. Lett. 486, 53-59.

Pertin, M., Ji, R. R., Berta, T., Powell, A. J., Karchewski, L., Tate, S. N., et al. (2005). Upregulation of the voltage-gated sodium channel beta2 subunit in neuropathic pain models: characterization of expression in injured and non-injured primary sensory neurons. J. Neurosci. 25, 10970-10980.
Qu, Y., Curtis, R., Lawson, D., Gilbride, K., Ge, P., DiStefano, P. S., et al. (2001). Differential modulation of sodium channel gating and persistent sodium currents by the betal, beta2, and beta 3 subunits. Mol. Cell. Neurosci. 18, 570-580.

Schmidt, J., Rossie, S., and Catterall, W. A. (1985). A large intracellular pool of inactive $\mathrm{Na}$ channel alpha subunits in developing rat brain. Proc. Natl. Acad. Sci. U.S.A. 82, 4847-4851.

Schmidt, J. W., and Catterall, W. A. (1987). Palmitylation, sulfation, and glycosylation of the alpha subunit of the sodium channel. Role of posttranslational modifications in channel assembly. J. Biol. Chem. 262, 13713-13723.

Shigetomi, E., Tong, X., Kwan, K. Y., Corey, D. P., and Khakh, B. S. (2011). TRPA1 channels regulate astrocyte resting calcium and inhibitory synapse efficacy through GAT-3. Nat. Neurosci. 15, 70-80.

Srinivasan, J., Schachner, M., and Catterall, W. A. (1998). Interaction of voltage-gated sodium channels with the extracellular matrix molecules tenascin- $\mathrm{C}$ and tenascinR. Proc. Natl. Acad. Sci. U.S.A. 95, 15753-15757.

Vassanelli, S., and Fromherz, P. (1997). Neurons from rat brain coupled to transistors. Appl. Phys. A 65, 85-88.
Westenbroek, R. E., Merrick, D. K., and Catterall, W. A. (1989). Differential subcellular localization of the RI and RII $\mathrm{Na}+$ channel subtypes in central neurons. Neuron 3, 695-704.

Wong, H. K., Sakurai, T., Oyama, F., Kaneko, K., Wada, K., Miyazaki, H., et al. (2005). Beta subunits of voltage-gated sodium channels are novel substrates of beta-site amyloid precursor protein-cleaving enzyme (BACE1) and gamma-secretase. J. Biol. Chem. 280, 23009-23017.

Xiao, Z. C., Ragsdale, D. S., Malhotra, J. D., Mattei, L. N., Braun, P. E., Schachner, M., et al. (1999). Tenascin-R is a functional modulator of sodium channel beta subunits. J. Biol. Chem. 274, 26511-26517.

Yu, F. H., Westenbroek, R. E., SilosSantiago, I., McCormick, K. A., Lawson, D., Ge, P., et al. (2003). Sodium channel beta4, a new disulfide-linked auxiliary subunit with similarity to beta2. J. Neurosci. 23, 7577-7585.

Zimmer, T., Biskup, C., Bollensdorff, C., and Benndorf, K. (2002). The betal subunit but not the beta2 subunit colocalizes with the human heart $\mathrm{Na}+$ channel (hH1) already within the endoplasmic reticulum. J. Membr. Biol. 186, 13-21.
Ziv, N. E., and Smith, S. J. (1996). Evidence for a role of dendritic filopodia in synaptogenesis and spine formation. Neuron 17, 91-102.

Conflict of Interest Statement: The authors declare that the research was conducted in the absence of any commercial or financial relationships that could be construed as a potential conflict of interest.

Received: 24 July 2012; accepted: 07 January 2013; published online: 25 January 2013.

Citation: Maschietto M, Girardi S, Dal Maschio $M$, Scorzeto $M$ and Vassanelli $S$ (2013) Sodium channel $\beta 2$ subunit promotes filopodia-like processes and expansion of the dendritic tree in developing rat hippocampal neurons. Front. Cell. Neurosci. 7:2. doi: 10.3389/ fncel.2013.00002

Copyright (C) 2013 Maschietto, Girardi, Dal Maschio, Scorzeto and Vassanelli. This is an open-access article distributed under the terms of the Creative Commons Attribution License, which permits use, distribution and reproduction in other forums, provided the original authors and source are credited and subject to any copyright notices concerning any third-party graphics etc. 